BMJ Open

Diabetes

Research

\& Care

\title{
Clinical characteristics and outcomes of symptomatic and asymptomatic hypoglycemia in hospitalized patients with diabetes
}

\author{
Saumeth Cardona, ${ }^{1}$ Patricia C Gomez, ${ }^{1}$ Priyathama Vellanki, ${ }^{1}$ Isabel Anzola, ${ }^{1}$ \\ Clementina Ramos, ${ }^{1}$ Maria A Urrutia, ${ }^{1}$ Jeehea Sonya Haw, ${ }^{1}$ Maya Fayfman, ${ }^{1}$ \\ Heqiong Wang, ${ }^{2}$ Rodolfo J Galindo, ${ }^{1}$ Francisco J Pasquel, ${ }^{1}$ Guillermo E Umpierrez ${ }^{1}$
}

To cite: Cardona $\mathrm{S}$, Gomez PC, Vellanki P, et al. Clinical characteristics and outcomes of symptomatic and asymptomatic hypoglycemia in hospitalized patients with diabetes. BMJ Open Diab Res Care 2018;6:e00607. doi:10.1136/ bmjdrc-2018-000607

SC and PCG contributed equally.

Partial data from this trial were presented at the American Diabetes Association meeting in (San Diego, California, USA), June 2017.

Received 30 August 2018 Revised 30 0ctober 2018 Accepted 16 November 2018

Check for updates

(c) Author(s) (or their employer(s)) 2018. Re-use permitted under CC BY-NC. No commercial re-use. See rights and permissions. Published by BMJ.

${ }^{1}$ Department of Medicine, Emory University School of Medicine, Atlanta, Georgia, USA ${ }^{2}$ Rollins School of Public Health, Emory University School of Medicine, Atlanta, Georgia, USA

Correspondence to Professor Guillermo E Umpierrez; geumpie@emory.edu

\section{ABSTRACT}

Importance The frequency and impact of asymptomatic hypoglycemia in hospitalized patients with diabetes is not known.

Objective We determined the clinical characteristics and hospital outcomes of general medicine and surgery patients with symptomatic and asymptomatic hypoglycemia.

Research design and methods Prospective observational study in adult patients with diabetes and blood glucose $(B G)<70 \mathrm{mg} / \mathrm{dL}$. Participants were interviewed about signs and symptoms of hypoglycemia using a standardized questionnaire. Precipitating causes, demographics, insulin regimen, and complications data during admission was collected.

Results Among 250 patients with hypoglycemia, 112 (44.8\%) patients were asymptomatic and 138 (55.2\%) had symptomatic hypoglycemia. Patients with asymptomatic hypoglycemia were older $(59 \pm 11$ years vs $54.8 \pm 13$ years, $p=0.003)$, predominantly males $(63 \%$ vs $48 \%, p=0.014)$, and had lower admission glycosylated hemoglobin $(8.2 \% \pm 2.6 \%$ vs $9.1 \pm 2.9 \%, p=0.006)$ compared with symptomatic patients. Compared with symptomatic patients, those with asymptomatic hypoglycemia had higher mean $B G$ during the episode $(60.0 \pm 8 \mathrm{mg} / \mathrm{dL}$ vs $53.8 \pm 11 \mathrm{mg} / \mathrm{dL}, \mathrm{p}<0.001)$. In multivariate analysis, male gender (OR 2.08, 95\% $\mathrm{Cl} 1.13$ to $3.83, \mathrm{p}=0.02$ ) and age $>65$ years (OR $4.01,95 \% \mathrm{Cl} 1.62$ to $9.92, p=0.02$ ) were independent predictors of asymptomatic hypoglycemia. There were no differences in clinical outcome, composite of hospital complications ( $27 \%$ vs $22 \%, p=0.41$ ) or inhospital length of stay (8 days (IQR 4-14) vs 7 days (IQR $5-15), p=0.92)$ ) between groups.

Conclusions Asymptomatic hypoglycemia was common among insulin-treated patients with diabetes but was not associated with worse clinical outcome compared with patients with symptomatic hypoglycemia. Older age and male gender were independent risk factors for asymptomatic hypoglycemia.

\section{INTRODUCTION}

Clinical guidelines for the management of hospitalized patients with diabetes define hypoglycemia as blood glucose lower than 70

\section{Significance of this study}

What is already known about this subject?

- Hypoglycemia is a common complication in hospitalized patients, reported in up to one-third of general medicine and surgery patients treated with insulin. Inpatient hypoglycemia has been associated with increased morbidity and mortality.

What are the new findings?

- In this prospective observational study, we found that $45 \%$ of insulin-treated patients with blood glucose $<70 \mathrm{mg} / \mathrm{dL}$ had asymptomatic hypoglycemia.

> In multivariate analysis, older age and male gender were associated with higher risk of asymptomatic hypoglycemia.

How might these results change the focus of research or clinical practice?

- Our results support current guideline recommendations on the need for blood glucose monitoring in insulin-treated patients in general wards.

- Clinicians should be aware of the high incidence of hypoglycemia, which has been associated with increased incidence of hospital complications compared with patients without hypoglycemia.

$\mathrm{mg} / \mathrm{dL} \cdot{ }^{12}$ Hypoglycemia is the most common complication of intensified insulin treatment and represents a major barrier to satisfactory long-term glycemic control. ${ }^{34}$ In randomized clinical trials, the reported incidence of hypoglycemia in the intensive care unit (ICU) has ranged between $5 \%$ and $28 \%,{ }^{5-8}$ and a similar prevalence has been reported in the non-ICU settings, where $5 \%-32 \%$ of patients treated with insulin develop hypoglycemia. ${ }^{4-13} \mathrm{~A}$ large body of evidence indicates a strong association between the development of hypoglycemia and poor clinical outcomes. ${ }^{14-17}$ Turchin et al reported that patients with inpatient hypoglycemia experienced a $66 \%$ 
increased risk of death within 1 year and spent 2.8 days longer in hospital compared with those without hypoglycemia. ${ }^{15}$ In addition, numerous retrospective and intervention studies in the general medicine and surgery services reported that hypoglycemia was associated with increased length of stay (LOS), need for ICU admission, and hospital mortality. ${ }^{15} 1618-21$

Bedside capillary point of care (POC) testing is recommended as the preferred method for glucose monitoring and for guiding glycemic management of patients in non-ICU settings. ${ }^{22}$ POC testing is usually performed before meals and at bedtime for patients who are eating or every 4-6 hours for patients who are not eating or receiving continuous enteral nutrition. ${ }^{17}$ Recent studies using continuous glucose monitoring in the hospital have reported that the current practice of measuring POC testing frequently misses episodes of hypoglycemia ${ }^{23-26}$ and that over a quarter of episodes $26.3 \%$ of hypoglycemia events were asymptomatic and not recognized by POC testing. ${ }^{23} 27$

To investigate the clinical characteristics of hospitalized patients with asymptomatic and symptomatic hypoglycemia and its impact on clinical outcome, we designed an alert system of hypoglycemic events to prospectively interview patients with $\mathrm{BG}<70 \mathrm{mg} / \mathrm{dL}$ about signs and symptoms of hypoglycemia using a standardized and validated questionnaire.

\section{SUBJECTS AND METHODS}

This was a single-center, prospective study in 250 general medicine and surgery patients with diabetes who experienced hypoglycemia during the hospital stay. Patients with a known history of type 1 or type 2 diabetes and age between 18 years and 80 years were recruited from general medicine and surgery services at Grady Memorial Hospital and Emory University Hospital in Atlanta, Georgia, between April 2015 and August 2016. Patients without a known history of diabetes, pregnancy, and those unable to provide consent or understand the questionnaire questions were excluded.

The nursing staff and laboratory personnel were instructed to immediately notify our research team for all patients with a $\mathrm{BG}<70 \mathrm{mg} / \mathrm{dL}$ during weekdays, by either laboratory value or by POC testing. The study team approached patients after reviewing medical records and confirming the diagnosis of diabetes and treatment regimen. After providing written informed consent, patients were asked about the presence of symptoms and signs of hypoglycemia using a standardized questionnaire adapted from studies by Cox $e t a l^{28}$ as well as information on potential precipitating cause(s) and hospital insulin regimen. Most patients were seen within 2 hours of the event and all patients within 4 hours of detection of blood glucose values. Symptoms were collected only during the first hypoglycemia episode, and no information was collected during subsequent events. Symptoms were categorized as neurogenic/adrenergic or neuroglycopenic.
The study team collected information on: (1) admission service, admitting diagnosis and demographic information, (2) hyperglycemia treatment, (3) number of hypoglycemic episodes by point-of-care testing or laboratory during hospital stay following indexed event, (4) history of hypoglycemia before admission in the ambulatory setting, (5) glycosylated hemoglobin (HbAlc) on admission or within the last 3 months prior to admission, (6) outpatient diabetes treatment, (7) treatment of indexed hypoglycemia episode, (8) value of POC glucose testing following the event, and (9) risk factors for hypoglycemia including impaired kidney and liver function, presence of infection, and use of antibiotics or beta-blockers. The study team also examined patients' hospital outcomes including: LOS, mortality, cardiovascular events (myocardial infarction and arrhythmias), nosocomial infections, pneumonia, bacteremia, respiratory failure, and acute kidney injury (defined as increase in serum creatinine by $50 \%$ or more from baseline). We report a composite of complications, including: cardiovascular events, infections, respiratory failure, and acute kidney injury, need for surgical reintervention, stroke, gastrointestinal bleeding, and blood transfusions.

\section{Statistical analysis}

We quantified demographics and clinical characteristics of patients with hypoglycemia with and without symptoms. For continuous variables, depending on normality of data, Student's t-tests or non-parametric Wilcoxon tests were used to assess the differences between those with symptomatic and asymptomatic hypoglycemia. For discrete variables, $\chi^{2}$ tests or Fisher's exact tests was used to examine differences between those with symptomatic and asymptomatic hypoglycemia. We used logistic regression to identify predictors of asymptomatic hypoglycemia. The following covariates were included: age, gender, HbA1c, estimated glomerular filtration rate, body mass index (BMI), and blood glucose level at time of event. All tests were two sided, with statistical significance set at $\mathrm{p}<0.05$. Statistical analyses were conducted using SAS, V.9.3.

\section{RESULTS}

\section{Baseline demographic and clinical characteristics}

The study cohort consisted of 250 patients with diabetes who developed hypoglycemia during hospitalization. The baseline demographic and clinical characteristics of the overall cohort are shown in table 1 . The population consisted of middle-age adults (mean age $56.7 \pm 12$ years), mostly African-Americans ( $81 \%$ ) and male gender (55\%). Most patients had type 2 diabetes (93\%), a mean duration of diabetes of $13.9 \pm 9$ years, $85 \%$ of patients were admitted to medicine services and the mean admission $\mathrm{HbAlc}$ was $8.7 \% \pm 2.8$. The LOS was 8 days (IQR: $4-15$ ). The mean admission BG was $236 \pm 173 \mathrm{mg} / \mathrm{dL}$. The average BG on the day before the hypoglycemic event was $154 \pm 66 \mathrm{mg} /$ $\mathrm{dL}$. The average BG during the hypoglycemia event for 
Table 1 Demographic and clinical characteristic of patients with hypoglycemia

\begin{tabular}{|c|c|c|c|}
\hline Characteristics & $\begin{array}{l}\text { Symptomatic } \\
138(55 \%)\end{array}$ & $\begin{array}{l}\text { Asymptomatic } \\
112(45 \%)\end{array}$ & $P$ values \\
\hline Age, years & $54.8 \pm 12.7$ & $59.0 \pm 10.6$ & 0.003 \\
\hline Gender & & & 0.014 \\
\hline Female & $72(52)$ & $41(37)$ & \\
\hline Male & $66(48)$ & $71(63)$ & \\
\hline Race & & & 0.37 \\
\hline African-American & $110(80)$ & $90(81)$ & \\
\hline Hispanic & $7(5)$ & $6(5)$ & \\
\hline White & $19(14)$ & $11(10)$ & \\
\hline Other & $1(1)$ & $4(4)$ & \\
\hline Admission $\mathrm{HbA} 1 \mathrm{c}, \%$ & $9.1 \pm 2.9$ & $8.2 \pm 2.6$ & 0.006 \\
\hline Duration of diabetes, years & $13.8 \pm 9.1$ & $14 \pm 9.3$ & 0.79 \\
\hline \multicolumn{4}{|l|}{ Diabetes (DM) type } \\
\hline DM type 1 & $11(8)$ & $6(5)$ & 0.46 \\
\hline DM type 2 & $127(92)$ & $106(95)$ & \\
\hline \# Hypo events, median & $2.0(1.0,4.0)$ & $2.0(1.0,3.0)$ & 0.009 \\
\hline Admission BG, mg/dL & $248.2 \pm 183$ & $220.7 \pm 159$ & 0.43 \\
\hline Outpatient diabetes treatment & & & 0.24 \\
\hline No treatment & $6(4)$ & $6(5)$ & \\
\hline Diet only & $8(6)$ & $14(13)$ & \\
\hline Insulin only & $80(58)$ & $51(46)$ & \\
\hline OAD/GLP1 only & $21(15)$ & $20(18)$ & \\
\hline OAD/GLP1+insulin & $23(17)$ & $20(18)$ & \\
\hline \multicolumn{4}{|l|}{ Hospital diabetes treatment } \\
\hline Basal+SSI & $45(33)$ & $26(23)$ & 0.10 \\
\hline Basal+bolus & $61(44)$ & $48(43)$ & 0.83 \\
\hline Basal+bolus+OAD & $0(0)$ & $2(2)$ & 0.20 \\
\hline SSI only & $18(13)$ & $16(14)$ & 0.78 \\
\hline OAD+basal insulin & $2(1)$ & $8(7)$ & 0.046 \\
\hline $\mathrm{OAD}+\mathrm{SSI}$ & $3(2)$ & $0(0)$ & 0.26 \\
\hline GLP1+SSI & $0(0)$ & $1(1)$ & 0.44 \\
\hline No treatment & $9(7)$ & $11(10)$ & 0.36 \\
\hline \multicolumn{4}{|l|}{ Blood glucose during hypoglycemia episode } \\
\hline Mean BG during hypoglycemia, mg/dL & $53.8 \pm 11.4$ & $60.0 \pm 8.3$ & $<0.001$ \\
\hline BG values between $60 \mathrm{mg} / \mathrm{dL}$ and $69 \mathrm{mg} / \mathrm{dL}, \mathrm{n}(\%)$ & $58(42)$ & $73(65)$ & \\
\hline BG values between $40 \mathrm{mg} / \mathrm{dL}$ and $59 \mathrm{mg} / \mathrm{dL}, \mathrm{n}(\%)$ & $63(46)$ & $37(33)$ & \\
\hline BG values $<54$ mg/dL, n (\%) & $60(43)$ & $22(20)$ & \\
\hline BG values $<40 \mathrm{mg} / \mathrm{dL}, \mathrm{n}(\%)$ & $17(12)$ & $2(2)$ & \\
\hline
\end{tabular}

Data are $\mathrm{n}(\%)$, mean $\pm \mathrm{SD}$ or median $(\mathrm{IQR})$.

To convert $\mathrm{HbA} 1 \mathrm{c}$ value in $\%$ to $\mathrm{mmol} / \mathrm{mol}=10.93 \times \% \mathrm{HbA} 1 \mathrm{c}$ value -23.5$)$, BG value in $\mathrm{mg} / \mathrm{dlL}$ to $\mathrm{mmol} / \mathrm{L}=\mathrm{BG} \mathrm{mg} / \mathrm{dL}$ value $/ 18$.

DM, diabetes mellitus;BG, blood glucose; GLP-1, Glucagon-like peptide 1; OAD, Oral antidiabetic drug; SSI, sliding scale insulin.

the entire cohort was $56.6 \pm 10.6 \mathrm{mg} / \mathrm{dL}$. A total of 131 (52\%) had a BG between $60 \mathrm{mg} / \mathrm{dL}$ and $69 \mathrm{mg} / \mathrm{dL}, 82$ $(33 \%)$ had a $\mathrm{BG}<54 \mathrm{mg} / \mathrm{dL}$, and $19(8 \%)$ had a $\mathrm{BG}<40$ $\mathrm{mg} / \mathrm{dL}$.

There were no differences in baseline clinical characteristics between patients with or without hypoglycemic symptoms including BMI, race, previous antidiabetic treatment, type of diabetes, diabetes duration, admission service, renal failure, liver failure, heart failure, betablockers or antibiotics use or oral intake status; the median number of hypoglycemia episodes was statistically significant $(p=0.009)$ but not of clinical significance (tables 1-2).

Patients with asymptomatic hypoglycemia were older ( $59 \pm 10.6$ years vs $54.8 \pm 12.7$ years, $\mathrm{p}=0.003$ ), more likely to be male $(63 \%$ vs $37 \%, \mathrm{p}=0.014)$ and had lower admission 
Table 2 Risk factors and hospital complications in patients with symptomatic and asymptomatic hypoglycemia

\begin{tabular}{|c|c|c|c|}
\hline & Symptomatic hypoglycemia & $\begin{array}{l}\text { Asymptomatic } \\
\text { hypoglycemia }\end{array}$ & $P$ values \\
\hline \multicolumn{4}{|l|}{ Risk factors } \\
\hline Reduced oral intake & 49 (39) & $48(48)$ & 0.15 \\
\hline eGFR $<60$ at time of episode & $69(51)$ & $62(56)$ & 0.42 \\
\hline Liver disease & $7(5)$ & $3(3)$ & 0.52 \\
\hline Heart failure & $29(21)$ & $16(14)$ & 0.17 \\
\hline Infection & $50(36)$ & $33(31)$ & 0.33 \\
\hline \multicolumn{4}{|l|}{ Other medications } \\
\hline Antibiotics & $45(33)$ & $35(31)$ & 0.82 \\
\hline Beta blockers & $47(34)$ & $45(40)$ & 0.32 \\
\hline History of previous hypoglycemia episodes & $0.2 \pm 0.4$ & $0.1 \pm 0.4$ & 0.44 \\
\hline \multicolumn{4}{|l|}{ Complications } \\
\hline Inpatient complications & $30(22)$ & $29(27)$ & 0.41 \\
\hline Cardiovascular event & $4(3)$ & $6(5)$ & 0.35 \\
\hline Nosocomial infection & $4(3)$ & $6(5)$ & 0.35 \\
\hline Respiratory failure & $0(0)$ & $6(5)$ & 0.0075 \\
\hline Acute kidney injury & $16(12)$ & $16(14)$ & 0.53 \\
\hline Stroke & $0(0)$ & $2(2)$ & 0.20 \\
\hline Gastrointestinal bleed & $1(1)$ & $2(2)$ & 0.59 \\
\hline Transfusion & $0(0)$ & $3(3)$ & 0.09 \\
\hline
\end{tabular}

Data are $\mathrm{n}(\%)$.

eGFR, estimated glomerular rate filtration.

HbAlc $(8.2 \% \pm 2.6$ vs $9.1 \% \pm 2.9$, $\mathrm{p}=0.006)$, compared with patients with symptomatic hypoglycemia (table 2). The glucose level during the hypoglycemia episode was higher in patients with asymptomatic hypoglycemia compared with patients with symptomatic hypoglycemia $(60 \pm 8.3 \mathrm{vs}$ $53.8 \pm 11.4 \mathrm{mg} / \mathrm{dL}, \mathrm{p}=<0.001)$. Among patients with symptomatic hypoglycemia, most commonly reported symptoms were adrenergic symptoms such as sweating (61\%), trembling $(55 \%)$, and anxiety $(52 \%)$, followed by confusion or difficulty in concentration $(52 \%)$, and dry mouth (44\%), table 3 .

A total of 59 patients $(24 \%)$ experienced $\geq 1$ hospital complications during the hospital stay. There were no differences in complications $(27 \%$ vs $22 \%, p=0.41)$, table 3 or in the hospital LOS (8 days (IQR 4-14) vs 7 days (IQR 5-15), $\mathrm{p}=0.92$ ) between patients with asymptomatic and symptomatic hypoglycemia. There were no differences in the hospital treatment or type of insulin regimen between groups except for hospital treatment with oral agents and insulin ( $\mathrm{p}-0.0461)$.

\section{Hypoglycemia risk factors}

A total of $131(53 \%)$ patients with hypoglycemia had a glomerular filtration rate $<60 \mathrm{~mL} / \mathrm{min}$ at time of the hypoglycemic episode, 97 patients $(43 \%)$ had poor oral intake or were nil per os (NPO) at some point during the admission, other risk factors and concomitant medications are described in table 2. Patients were treated in the hospital with basal-bolus insulin regimen, basal plus correctional insulin per sliding scale (SSI), or combination of insulin and oral agents, or with sliding-insulin scale alone (table 1 ).

In multivariate analysis for predictors of asymptomatic hypoglycemia including age, gender, renal function, blood glucose, BMI and HbAlc value, we found that

\begin{tabular}{|c|c|}
\hline & $\mathrm{n}(\%)$ \\
\hline \multicolumn{2}{|l|}{ Adrenergic symptoms } \\
\hline Sweating & $79(61)$ \\
\hline Anxiety & $70(52)$ \\
\hline Trembling & $72(55)$ \\
\hline Dry mouth & $57(44)$ \\
\hline Hand coldness & $46(35)$ \\
\hline Heart pounding & $38(29)$ \\
\hline Hunger & $13(9)$ \\
\hline Nausea & $9(7)$ \\
\hline \multicolumn{2}{|l|}{ Neurological symptoms } \\
\hline Confusion/low concentration & $70(52)$ \\
\hline Blurred vision & $53(40)$ \\
\hline Slurred speech & $39(30)$ \\
\hline Numbness around lips & $21(16)$ \\
\hline Headache & $11(8)$ \\
\hline
\end{tabular}




\begin{tabular}{|c|c|c|}
\hline & OR & $(95 \% \mathrm{Cl})$ \\
\hline $\mathrm{HbA1C}$ & 0.94 & (0.84 to 1.05 ) \\
\hline Age $<50$ years & 1 (ref) & \\
\hline $50-58$ years & 1.73 & $(0.76$ to 3.96$)$ \\
\hline $59-64$ years & 2.55 & (1.11 to 5.84$)$ \\
\hline$\geq 65$ years & 4.01 & (1.62 to 9.92$)$ \\
\hline BG level during hypoglycemic event & 1.07 & $(1.04$ to 1.1$)$ \\
\hline Male gender & 2.08 & $(1.13$ to 3.83$)$ \\
\hline GFR $\geq 60$ versus $G F R<60$ & 0.70 & (0.39 to 1.26$)$ \\
\hline BMI & 0.99 & (0.95 to 1.02$)$ \\
\hline
\end{tabular}

BG, blood glucose; BMI, body mass index; GFR, glomerular filtration rate; $\mathrm{HbA1C}$, glycosylated hemoglobin.

older age and male gender were independent predictors of asymptomatic hypoglycemia, with men having two times higher odds than women (OR 2.08, CI 1.13 to 3.83, $\mathrm{p}=0.02$ ) (table 4). These relationships were independent of glucose levels at the time of the indexed event. In multivariate analysis adjusted for age, gender, renal function, LOS, and race, we found no significant association between a composite of complications and asymptomatic hypoglycemia $(\mathrm{p}=0.7)$.

\section{DISCUSSION}

The results of this prospective observational study indicate that asymptomatic hypoglycemia is observed in almost half of insulin-treated general medicine and surgery patients with diabetes. Age and male gender were identified as independent predictors of asymptomatic hypoglycemia, with males having two-times higher odds than females, and older patients $\geq 65$ years having fourfold higher odds of asymptomatic hypoglycemia compared with younger patients. There were no differences in hospital-related complications or duration in LOS between patients with or without hypoglycemia symptoms.

According to Endocrine Society and the American Diabetes Association guidelines, ${ }^{29}$ inpatient hypoglycemia is defined as a $B G \leq 70 \mathrm{mg} / \mathrm{dL}$, which may be independent of the presence of adrenergic or neurological symptoms. The threshold at which patients experience symptoms varies from person to person and depends primarily on the severity of hypoglycemia. In our study, we observed that the average BG in patients with symptomatic hypoglycemia was $53.8 \pm 11 \mathrm{mg} / \mathrm{dL}$, and asymptomatic event had a BG of $60.0 \pm 8 \mathrm{mg} / \mathrm{dL}$ and that most patients with glucose values above $50 \mathrm{mg} / \mathrm{dL}$ had asymptomatic events. These results support the recent International Hypoglycemia Study Group report, which recommended a glucose concentrations of less than 3.0 $\mathrm{mmol} / \mathrm{L}(54 \mathrm{mg} / \mathrm{dL}$ ) to be considered as clinical significant hypoglycemic event and that a blood glucose level of $<70 \mathrm{mg} / \mathrm{dL}$ should only be considered an alert value and may be used as a threshold for further titration of insulin regiment. ${ }^{30} 31$

Previous studies have reported that increasing age is an independent risk factor for the development of hypoglycemia in insulin-treated patients with type 2 diabetes. ${ }^{4}$ It has also been shown that elderly patients frequently fail to communicate symptoms of hypoglycemia to hospital staff ${ }^{32}$ and develop hypoglycemic symptoms at a significantly lower glucose concentration compared with younger patients. ${ }^{33}$ These factors often lead to more prolonged and more severe hypoglycemia in the elderly. In agreement with these reports, older patients were more likely to have asymptomatic events and that age of 65 years (OR $4.08,95 \%$ CI 1.65 to $10.07, \mathrm{p}=0.01$ ) was an independent predictor of asymptomatic hypoglycemia. Implementing the strategies to reduce hypoglycemia, either by avoidance of intensive glycemic control or using agents associated with lower rates of hypoglycemia, ${ }^{17} 34$ can lead to significant reduction in hypoglycemia rates, improvement in patient's safety and overall quality of care in elderly population.

Our study has several of strengths. This is the first prospective study aimed to determine the frequency of asymptomatic hypoglycemia in insulin-treated hospitalized patients in general wards. We used a validated outpatient instrument to score symptoms of hypoglycemia $^{28}$ with patients seen shortly after the episode of hypoglycemia. We recognize, however, several limitations including a selected population from a single academic institution, with a large population of African-Americans with type 2 diabetes. We limited POC testing to our standard of care before meals and bedtime. Newer technologies such as continuous glucose monitoring has been shown to provide a more comprehensive 24-hour glycemic evaluation and has been shown to be better than POC testing in recognizing episodes of hypoglycemia in insulin-treated patients in the hospital. ${ }^{23}$ In addition, we did not collect information to determine if asymptomatic individuals had hypoglycemia unawareness. Future studies using continuous glucose monitoring may help to identify a larger number and durations of asymptomatic events. ${ }^{23} 29$

\section{CONCLUSION}

In summary, the results of this prospective study indicate asymptomatic hypoglycemia is common and is present in about half of insulin-treated patients with diabetes in general wards. In multivariate analysis, male gender and age $\geq 65$ years were independent predictors of asymptomatic hypoglycemia. There were no differences in clinical outcome, composite of hospital complications or in hospital LOS between patients with asymptomatic hypoglycemia compared with patients with symptomatic presentation.

Acknowledgements The present study was supported by an unrestricted grant from the Jacobs Family Research Fund to Emory University and GEU. 
Contributors GEU is the guarantor of this work and, as such, had full access to all the data in the study and takes responsibility for the integrity of the data and the accuracy of the data analysis. GEU wrote the initial research proposal. PCG, SC, and GEU wrote the manuscript. FJP, RJG, PV, IA, CR, MAU, JSH and MF reviewed/ edited the research proposal and manuscript and contributed to the discussion. HW conducted the statistical analysis.

Competing interests GEU is partly supported by research grants from the Public Health Service (grants UL1 TR002378 from the Clinical and Translational Science Award program and 1P30DK111024-01 from the National Institutes of Health and National Center for Research Resources). PV is supported by NIH grant: 3K12HD085850-03S1. GEU has received unrestricted research support for inpatient studies (to Emory University) from Merck, Novo Nordisk, AstraZeneca, Boehringer Ingelheim, and Sanofi. FJP and PV have received consulting fees from Boehringer Ingelheim and Merck. RJG has received unrestricted research support for inpatient studies (to Emory University) from Novo Nordisk and consulting fees from Abbott. SC, PCG, IA, CR, MAU, JSH, MF, and HW declared no conflicts of interest.

Patient consent for publication Not required.

Provenance and peer review Not commissioned; externally peer reviewed.

Data sharing statement All the findings from available data have been published in this manuscript.

Open access This is an open access article distributed in accordance with the Creative Commons Attribution Non Commercial (CC BY-NC 4.0) license, which permits others to distribute, remix, adapt, build upon this work non-commercially, and license their derivative works on different terms, provided the original work is properly cited, appropriate credit is given, any changes made indicated, and the use is non-commercial. See: http://creativecommons.org/licenses/by-nc/4.0

\section{REFERENCES}

1. American Diabetes Association. 14. Diabetes care in the hospital: standards of medical care in diabetes-2018. Diabetes Care 2018;41:S144-S151.

2. Garber AJ, Abrahamson MJ, Barzilay JI, et al. CONSENSUS statement by the american association of clinical endocrinologists and american college of endocrinology on the comprehensive type 2 diabetes management algorithm - 2018 executive summary. Endocr Pract 2018;24:91-120.

3. Boucai L, Southern WN, Zonszein J. Hypoglycemia-associated mortality is not drug-associated but linked to comorbidities. Am J Med 2011;124:1028-35.

4. Farrokhi F, Klindukhova O, Chandra P, et al. Risk factors for inpatient hypoglycemia during subcutaneous insulin therapy in non-critically ill patients with type 2 diabetes. J Diabetes Sci Technol 2012;6:1022-9.

5. Krikorian A, Ismail-Beigi F, Moghissi ES. Comparisons of different insulin infusion protocols: a review of recent literature. Curr Opin Clin Nutr Metab Care 2010;13:198-204.

6. Bersoux S, Cook CB, Kongable GL, et al. Benchmarking glycemic control in u.s. Hospitals. Endocr Pract 2014;20:876-83.

7. Yamada T, Shojima N, Noma H, et al. Glycemic control, mortality, and hypoglycemia in critically ill patients: a systematic review and network meta-analysis of randomized controlled trials. Intensive Care Med 2017;43:1-15.

8. Mahmoodpoor A, Hamishehkar H, Beigmohammadi M, et al. Predisposing factors for hypoglycemia and its relation with mortality in critically ill patients undergoing insulin therapy in an intensive care unit. Anesth Pain Med 2016;6:e33849.

9. Umpierrez GE, Jones S, Smiley D, et al. Insulin analogs versus human insulin in the treatment of patients with diabetic ketoacidosis: a randomized controlled trial. Diabetes Care 2009;32:1164-9.

10. Umpierrez GE, Smiley D, Jacobs S, et al. Randomized study of basal-bolus insulin therapy in the inpatient management of patients with type 2 diabetes undergoing general surgery (RABBIT 2 surgery). Diabetes Care 2011;34:256-61.

11. Umpierrez GE, Smiley D, Zisman A, et al. Randomized study of basal-bolus insulin therapy in the inpatient management of patients with type 2 diabetes (RABBIT 2 trial). Diabetes Care 2007;30:2181-6.

12. Bellido V, Suarez L, Rodriguez MG, et al. Comparison of basal-bolus and premixed insulin regimens in hospitalized patients with type 2 diabetes. Diabetes Care 2015;38:2211-6.
13. Bueno E, Benitez A, Rufinelli JV, et al. Basal-bolus regimen with insulin analogues versus human insulin in medical patients with type 2 diabetes: A randomized controlled trial in Latin America. Endocr Pract 2015;21:807-13.

14. Desouza CV, Bolli GB, Fonseca V. Hypoglycemia, diabetes, and cardiovascular events. Diabetes Care 2010;33:1389-94.

15. Turchin A, Matheny ME, Shubina M, et al. Hypoglycemia and clinical outcomes in patients with diabetes hospitalized in the general ward. Diabetes Care 2009;32:1153-7.

16. Kagansky N, Levy S, Rimon E, et al. Hypoglycemia as a predictor of mortality in hospitalized elderly patients. Arch Intern Med 2003;163:1825-9.

17. Umpierrez GE, Hellman R, Korytkowski MT, et al. Management of hyperglycemia in hospitalized patients in non-critical care setting: an endocrine society clinical practice guideline. J Clin Endocrinol Metab 2012;97:16-38.

18. Fischer KF, Lees JA, Newman JH. Hypoglycemia in hospitalized patients. Causes and outcomes. N Engl J Med 1986;315:1245-50.

19. Stagnaro-Green A, Barton MK, Linekin PL, et al. Mortality in hospitalized patients with hypoglycemia and severe hyperglycemia. Mt Sinai J Med 1995;62:422-6.

20. Garg R, Hurwitz S, Turchin A, et al. Hypoglycemia, with or without insulin therapy, is associated with increased mortality among hospitalized patients. Diabetes Care 2013;36:1107-10.

21. Akirov A, Grossman A, Shochat T, et al. Mortality among hospitalized patients with hypoglycemia: Insulin related and noninsulin related. $J$ Clin Endocrinol Metab 2017;102:416-24.

22. Moghissi ES, Korytkowski MT, DiNardo M, et al. American Association of Clinical Endocrinologists and American Diabetes Association consensus statement on inpatient glycemic control. Diabetes Care 2009;32:1119-31.

23. Gómez AM, Umpierrez GE, Muñoz OM, et al. Continuous glucose monitoring versus capillary point-of-care testing for inpatient glycemic control in type 2 diabetes patients hospitalized in the general ward and treated with a basal bolus insulin regimen. $J$ Diabetes Sci Technol 2015;10:325-9.

24. Beck RW, Riddlesworth T, Ruedy K, et al. Effect of continuous glucose monitoring on glycemic control in adults with type 1 diabetes using insulin injections: The diamond randomized clinical trial. JAMA 2017;317:371-8.

25. Rodbard D. Continuous glucose monitoring: A review of successes, challenges, and opportunities. Diabetes Technol Ther 2016;18(Suppl 2):S2-3-13.

26. Wallia A, Umpierrez GE, Rushakoff RJ, et al. Consensus statement on inpatient use of continuous glucose monitoring. J Diabetes Sci Technol 2017;11:1036-44.

27. Burt MG, Roberts GW, Aguilar-Loza NR, et al. Brief report: Comparison of continuous glucose monitoring and finger-prick blood glucose levels in hospitalized patients administered basalbolus insulin. Diabetes Technol Ther 2013;15:241-5.

28. Cox DJ, Gonder-Frederick L, Antoun B, et al. Perceived symptoms in the recognition of hypoglycemia. Diabetes Care 1993;16:519-27.

29. Seaquist ER, Anderson J, Childs B, et al. Hypoglycemia and diabetes: a report of a workgroup of the American Diabetes Association and the Endocrine Society. J Clin Endocrinol Metab 2013;98:1845-59.

30. Schwartz NS, Clutter WE, Shah SD, et al. Glycemic thresholds for activation of glucose counterregulatory systems are higher than the threshold for symptoms. J Clin Invest 1987;79:777-81.

31. International Hypoglycaemia Study Group. Glucose concentrations of less than $3.0 \mathrm{mmol} / \mathrm{l}(54 \mathrm{mg} / \mathrm{dl})$ should be reported in clinical trials: A joint position statement of the american diabetes association and the european association for the study of diabetes. Diabetes Care 2017;40:155-7.

32. Kulasa K, Juang P. How low can you go? Reducing rates of hypoglycemia in the non-critical care hospital setting. Curr Diab Rep 2017;17:74.

33. Matyka K, Evans M, Lomas J, et al. Altered hierarchy of protective responses against severe hypoglycemia in normal aging in healthy men. Diabetes Care 1997;20:135-41.

34. Pasquel FJ, Gianchandani R, Rubin DJ, et al. Efficacy of sitagliptin for the hospital management of general medicine and surgery patients with type 2 diabetes (Sita-Hospital): a multicentre, prospective, open-label, non-inferiority randomised trial. Lancet Diabetes Endocrinol 2017:5:125-33. 